\title{
PAISAGENS INVISÍVEIS DA TRILOGIA NITECKI: DE ARISTÓTELES E PLATÃO A LENIN E TROTSKY
}

\author{
INVISIBLE LANDSCAPES OF THE NITECKI TRILOGY: \\ FROM ARISTOTLE AND PLATO TO LENIN AND \\ TROTSKY
}

Gustavo Silva Saldanha ${ }^{a}$

\begin{abstract}
RESUMO
Objetivo: A pesquisa investiga o método cartográfico-epistemológico da Trilogia Nitecki e seus principais resultados para a compreensão da epistemologia histórica da Ciência da Informação. Metodologia: Do ponto de vista metodológico, a pragmática da linguagem, sob influência wittgensteiniana para a pesquisa diacrônica, é a base da pesquisa, de cultura descritiva, com foco na reflexão sobre as epistemologias históricas do campo. A metáfora-ferramenta das cartografias, como um metamétodo, é aplicada como lente da análise. Tal metáfora-ferramenta é acompanhada pela narrativa do romancista e contista Ítalo Calvino em As Cidades Invisíveis. Resultados: $O$ (re)encontro com a Trilogia Nitecki nos conduz a alguns importantes elementos da epistemologia da Ciência da Informação e da reflexão sobre a própria tarefa metaepistemológica constituída nos anos 1990 pelo pesquisador, com destaque para a epistemologia histórica esquecida, a disputa terminológica do campo e a passagem do universal para o particular. Em contrapartida, observa-se criticamente os problemas da Trilogia, centralmente, a influência anglófona fechada, o não aprofundamento em cartografias anglófonas anteriores e a ausência de teoria crítica, ou da dialética como método metaepistemológico para uma leitura transversal da cartografia constituída pela estrada niteckiana. Conclusões: $O$ devir cartográfico-epistemológico do campo representa um dos elementos conclusivos centrais da pesquisa, a partir dos horizontes revisitados pela Trilogia Nitecki, junto à perspectiva diacrônica de seu letramento cartográfico. Indica-se, por fim, a necessidade de um devir anti-epistemicida a ser colocado como núcleo das cartografias críticas futuras da Ciência da Informação.
\end{abstract}

Descritores: Epistemologia da Ciência da Informação. Trilogia Nitecki. Cartografia epistemológica. Epistemologia histórica. Mapas do conhecimento.

\section{INTRODUÇÃO}

Ao chegar a uma nova cidade, o viajante reencontra um passado que não lembrava existir: a surpresa daquilo que você deixou de ser ou deixou de possuir revela-se nos lugares estranhos, não

\footnotetext{
a Doutor em Ciência da Informação pelo IBICT. Docente adjunto da Universidade Federal do Estado do Rio de Janeiro (UNIRIO).E-mail: gustavosilvasaldanha@gmail.com
} 
nos conhecidos (CALVINO, 2003, p. 14).

Em 2023 atingimos os 30 anos do início do projeto conhecido como Nitecky Trilogy, ou Trilogia Nitecki, reflexão epistemológico-histórica do pesquisador Joseph Z. Nitecki sobre o desenvolvimento das ideias da Ciência da Informação. O pesquisador nos conduz pela trama cartográfica do campo a partir das obras Metalibrarianship: A Model for Intellectual Foundations Of Library Information Science, de 1993; Philosophical Aspects Of Library Information Science In Retrospect, de 1995; e Philosophical Ancestry Of American Library Information Science, 1997. Não sendo a primeira, e resultando (indiretamente, na maioria dos casos) em um "momento epistemológico" do campo, com produção crescente na virada do século $X X$ para o $X X I$, encontramos aqui um fenômeno discursivo de destaque para a compreensão da Ciência da Informação, bem como uma metametodologia para o exercício dessa reflexão, pela via dos mapeamentos do conhecimento.

A ausência de reflexão sobre Nitecki e sua Trilogia é uma primeira, ainda que parcial e não prioritária, justificativa para o estudo (reconsiderada, por exemplo, pelo próprio fato da semelhante ausência de uma produção epistemológico-histórica sobre diferentes obras e trajetórias epistêmico-biobibliográficas em Ciência da Informação). O que enfatizamos no ato justificativo é, dada a complexidade e a vastidão do projeto niteckiano, sua rara presença no pensamento brasileiro e latino-americano de Ciência da Informação, incluindo a própria tradição internacional anglófona, parece-nos um aspecto relevante para o estudo (no plano sincrônico e no plano diacrônico).

Alguns momentos da argumentação epistemológica nos anos 1980 abriram caminhos, de modo relevante, do Brasil para o mundo, para esse percurso crítico-epistemológico. Tratamos, pois, da tese de Solange Mostafa, de 1985, e do artigo Fundamentos filosóficos da Biblioteconomia, de Sebastião de Souza (1986), antevendo a Trilogia no diálogo com as fontes que levam futuramente Nitecki $(1993,1995,1997)$ a constituir sua pesquisa de fôlego.

A reflexão filosófica, com foco epistemológico, aqui construída, é especificamente baseada na filosofia da linguagem ordinária, ou na pragmática da linguagem. Tal via epistemológica é fruto de três projetos transversais em 
curso vinculados à pesquisa filosófica em Ciência da Informação e às teorias críticas da organização do conhecimento (ou conjunto de práticas sobre o papel da linguagem e das metalinguagens na construção social do real).

Especificamente, os projetos em curso "Epistemologia histórica da Ciência da Informação e organização do conhecimento: dos fundamentos filosóficos da linguagem à teoria crítica da classificação" e Organização dos saberes no domínio de povos e comunidades tradicionais do Brasil: linguagens, tecnologias, instituições informacionais e integração pragmática de dados", financiados pelo CNPq, bem como "Linguagens documentárias fluminenses para a inovação: organização do conhecimento para ciência, cultura e sociedade no Estado do Rio de Janeiro", sob financiamento da Faperj.

Do ponto de vista metodológico, a pragmática da linguagem, sob influência wittgensteiniana (WITTGENSTEIN, 1979, 2002) para a pesquisa diacrônica é a base do resultado desta pesquisa, de cultura descritiva, com foco na reflexão sobre as epistemologias históricas do campo. A metáfora-ferramenta das cartografias, como um metamétodo do campo, é adotada-aplicada como lente da análise. Tal metáfora-ferramenta é acompanhada pela narrativa do romancista e contista Ítalo Calvino em As Cidades Invisíveis.

No plano da pragmática da linguagem, seguimos as trilhas de Wittgenstein (1979, p. 15). Aqui a linguagem - em nosso território, a metalinguagem -, materialidade co-constituinte do conhecimento, "pode ser considerada como uma velha cidade: uma rede de ruelas e praças, casas novas e velhas, e casas construídas em diferentes épocas; e isto tudo cercado por uma quantidade de novos subúrbios com ruas retas e regulares e com casas uniformes". Os mapas do conhecimento podem ser espelhados nessa metáforaferramenta das cidades-linguagem, abertas, em crescimento, em permanente reestruturação.

Nitecki (1993) procura em sua cartografia pelas cidades do pensamento informacional, de modo enciclopédico, identificar os aspectos filosóficos expressos na produção bibliográfica do campo biblioteconômico-informacional. Trata-se de uma busca por "fundamentos", ou a "base do conhecimento" de sua Library and Information Science. 
Em Mostafa (1985) encontramos um diálogo crítico sobre as bases dessa trajetória reflexiva que resulta na Trilogia, centralmente a aproximação aos trabalhos An idea of librarianship: an outline for a root-metaphor theory in library science, de 1981; bem como Metaphors of librarianship: a suggestion for a metaphysical model, de 1979, e Reflections on the nature and limits of library science, de 1968. Como observado, são percursos iniciais de um horizonte que guarda, nos anos 1990, potenciais e frutíferos diálogos com a produção do conhecimento epistemológico no campo junto de Nitecki, porém pouco desdobrados.

O que procuramos aqui é retomar alguns aspectos de tal produção dos anos 1990 e apontar caminhos, pontes e obstáculos de seu desenvolvimento. A descrição se concentra, nessa etapa, objetivamente, naquilo que nos apresenta o painel do propósito geral do projeto ou volume primário - Metalibrarianship: $A$ Model for Intellectual Foundations Of Library Information Science, de 1993 -, bem como os aportes do panorama analítico do volume intermediário Philosophical Aspects Of Library Information Science In Retrospect, de 1995. Cabe-nos, na travessia, trazer à superfície olhares epistemológico-históricos de nossa caminhada pela vastidão dos territórios visitados pela e na Trilogia. Sob a via da pragmática da investigação panorâmica wittgensteiniana, procuramos, pela linguagem cartográfica niteckiana, conhecer as (in)visibilidades do nosso campo.

\section{O PROJETO NITECKI: UM CATÁLOGO DE CATÁLOGOS EPISTEMOLÓGICOS}

O catálogo das formas é interminável: enquanto cada forma não encontra a sua cidade, novas cidades continuarão a surgir (CALVINO, 2003, p. 59).

Em Metalibrarianship: A Model for Intellectual Foundations Of Library Information Science, publicado em 1993, Nitecki fornece uma topografia para o ensaio-viagem em torno de uma historicidade de longa duração na constituição do pensamento informacional - ou seja, no plano internacional, sob uma terminologia hoje observada sob a expressão Library and Information Science -, o pesquisador desenvolve seu mapa do campo. 
Para Nitecki (1993), o conceito de metalibrarianship (metabiblioteconomia), lançando na Trilogia, não representa uma teoria, mas uma investigação sobre a natureza do campo. Como um conceito amplo, atua como guarda-chuva para o mapeamento de diferentes abordagens e interpretações sobre o conhecimento registrado e suas ações no mundo informacional. O foco da pesquisa é um exercício hermenêutico: uma interpretação reflexiva - metaepistêmica - do campo. Sua "navegação" está na passagem por diferentes semelhanças, diferenças, denominadores comuns das várias atividades de processamento de registros. O estudo vai da análise dos registros aos seus conteúdos.

As hipóteses niteckianas, bem como o solo filosófico de seu trabalho, podem ser assim reproduzidas:

- Nenhuma ideia é tomada como criada ou entendida isoladamente, ou seja, as ideias são interrelacionadas;

- As ideias são historicamente tecidas, ou seja, se desenvolvem no decurso do tempo social. Deste modo, postula-se a incompletude do conhecimento (um fenômeno sempre aberto, inacabável), em seu processo de resposta aos questionamentos anteriores (NITECKI, 1993).

Mesmo sendo o conhecimento da realidade fragmentado, a realidade pode ser compreendida como um sistema holístico singular neste posicionamento epistemológico. A aprendizagem de novos conhecimentos, nesse entendimento, parte da descoberta gradual de conhecimentos anteriormente constituídosesquecidos-rememorados. Dito de outro modo, na metáfora niteckiana, trata-se de um processo de encontrar peças adicionais em um quebra-cabeça em constante expansão (NITECKI, 1993), metáfora essa comum tanto na filosofia da linguagem wittgensteiniana (WITTGENSTEIN, 1979), como nas narrativas de Calvino (2003).

O objetivo geral do projeto niteckiano presente na Triologia é se perguntar sobre a essência da Ciência da Informação, incluindo as questões como o significado da informação, os princípios por trás da transferência de informação, preservação de antigas e novas ideias através do registro. Nitecki (1993) considerava, como pressuposto estrutural de sua proposta, o campo biblioteconômico-informacional como foco no estudo e na preservação de 
registros e seu conteúdo, independentemente de seus formatos, suportes, características, como o universo das plataformas vegetal ou eletrônica. 0 fenômeno da informação representa o horizonte.

O modelo proposto por Nitecki (1993) distingue a) teoria da disciplina, b) implementações (aplicações) e c) os aspectos filosóficos. No plano macro, a metalibrarianship é uma especulação metafísica sobre as características da produção bibliográfica do campo biblioteconômico-informacional, conjugando, no entanto, dedução e indução, diacronia e sincronia, para sua leitura epistemológico-histórica. Está em jogo também no pensamento niteckiano a natureza das relações entre o conteúdo das mensagens nos fenômenos chamados "portadores de informação" e sua interpretação conceitual pelo receptor de tais mensagens (os sujeitos). Cada interpretação aborda diferentes aspectos de tais relacionamentos.

No seu processo metametodológico, Nitecki (1993) observa que a relações de sentido no interior do campo são definidas em seus contextos de produção conceitual e interpretadas externamente via pontos de vista metafísicos, epistemológicos e éticos. As redes de relações entre suas estruturas internas e interpretações externas definem a metalibrarianship. Os valores práticos do modelo residem em fornecer uma visão sobre as funções intermediárias da práxis e na identificação de denominadores comuns.

Em termos detalhados, segundo Nitecki (1993),

(a) A essência metafísica se relaciona com as relações básicas entre os conceitos registrados e sua cognição. Eles definem as realidades finais da biblioteconomia;

(b) A natureza epistemológica das relações descreve os processos que estabelecem o equilíbrio das tendências empíricas de redução das ideias a dados, com as reivindicações metafísicas de sua existência independente. A validade epistemológica desses processos é determinada pela análise lógica;

(c) Os valores e propósitos éticos das operações da metalibrarianship são expressos por seus objetivos ideais de fornecer serviços satisfatórios, mas também objetivos, aos usuários do mundo informacional. Nesse sentido, o campo investigado por Joseph Nitecki é como uma cartografia intelectual, 
orientando as pessoas para ideias específicas (NITECKI, 1993).

No âmbito da metáfora metodológico-cartográfica, Nitecki (1993) aponta para o uso feito por R. J. Merikangas, em Theory and Practice of Library Client Interaction, publicado na revista The Reference Librarian, em 1987, às páginas 297-312. Aqui, a cartografia - os mapas do conhecimento - representa a atividade mental unificadora de organizar tudo em um mapa mental, desde a instrução (educação) bibliográfica até a descoberta de caminhos e esquemas de solução de problemas. Aqui, ainda, os sistemas bibliográficos são a materialização da rede de relações que permite compreender esse espaço cartográfico das ideias produzido e investigado pela Ciência da Informação.

O modelo dos mapas do conhecimento nos coloca diante de uma metáforaferramenta para a própria metacompreensão do campo - o estudo epistemológico em seus princípios, ou seja, a compreensão do modo como compreendemos o saber e o fazer informacionais. Se múltiplas e igualmente relevantes são as observações e os experimentos cartográficos na Ciência da Informação antes e depois dos trabalhos de Joseph Nitecki nos anos 1990, a extensão da Trilogia nos permite reeditar o devir cartográfico-epistêmico do campo, repensamento uma filosofia da linguagem wittgensteiniana (WITTGENSTEIN, 1979) como exercício metodológico para análises epistemológicas. Do mesmo modo, a Trilogia nos leva ao reencontro do epistemólogo e do agente informacional como um viajante - Marco Polo - a contar e recontar as descrições de paisagens de constituição, de expansão e de transformação do campo.

O percurso cartográfico niteckiano propõe-se, assim, compreender a travessia histórica de longa duração da Ciência da Informação definida a partir de três revoluções (do remoto ao atual), a invenção do alfabeto, o desenvolvimento da impressa e o que o autor considera ali, na segunda metade do século XX, a contemporânea "explosão da informação" (NITECKI, 1993).

Em Philosophical Aspects Of Library Information Science In Retrospect, de 1995, Joseph Nitecki, após estabelecer um modelo de intepretação filosófica da Ciência da Informação dois anos antes, desenvolve um estudo da representação de diferentes formas de visualização da filosofia do campo. Em um primeiro 
momento, Nitecki (1995) analisa amostras das principais contribuições (em sua revisão) de fundamentação da Ciência da Informação; posteriormente, as amostras são abstraídas. Seu percurso procura identificar os raros (conforme a posição dedutiva e indutiva do seu trabalho metodológico) modelos filosóficos no campo, sem abandonar o olhar sobre as práticas.

O mapeamento niteckiano atravessa as análises de construção da filosofia da Ciência da Informação, os princípios éticos presentes em sua literatura, as definições metafísicas de elementos categoriais da filosofia e da epistemologia biblioteconômico-informacionais - como bibliotecas, biblioteconomia, bibliotecários, informação, junto de muitos outros - e suas relações disciplinares com campos como, por exemplo, a Computação. Registra-se aqui o profundo mergulho na cartografia dos grandes conceitos e componentes principais de conformação da Ciência da Informação (via seu vocabulário), passando por livro (primeiro elemento indicado), bibliografia, instrução bibliográfica, censura, classificação e catalogação, comunicação, coleções, cooperação (compartilhamento), redes, relações entre dado, informação e conhecimento, tecnologia da informação, neutralidade, administração, mídia, leitura (NITECKI, 1995).

Integra também o debate da Trilogia, as questões relativas ao perfil profissional, o papel do profissional na sociedade, a educação no campo, os aspectos teóricos do domínio, as disciplinas e teorias relacionadas ao campo (aqui, Nitecki reúne ciências cognitivas, teoria do domínio de Kouzes e Mico, teoria geral dos sistemas, metateoria, teorias da informação, metaciência, teorias da administração, teoria de médio alcance, teorias das organizações, fenomenologia, teoria de Piaget, teoria do conhecimento objetivo de Karl Popper e Sociologia do Conhecimento); em outra direção, Nitecki (1995) identifica os modelos teóricos aderentes ao campo, a saber, Ciências da Informação e Computação, abordagem do senso comum, modelo comunicacional de Brenda Dervin, epistemologia de Barfield, epistemologia social de Jesse Shera, disciplinas epistêmico-dinâmicas, modelo genético e de dados, modelos informacionais, metrias de bibliotecas, modelos gerais de bibliotecas, modelo linguístico de comunicação, amostras de modelos mentais, a própria 
metabiblioteconomia de Nitecki, modelo de disciplina métrica, modelos de realidade, modelo do valor agregado de Taylor; por outro lado, ainda, Nitecki (1995) apresenta os princípios e leis do campo, com foco em leis cosmonômicas, hermenêutica, leis de Ranganathan, princípios de revocação e precisão, princípios de Zipf; por fim, no plano das investigações epistemológicas, encontramos os métodos do campo, com foco em andragogy (educação de adultos e formação continuada), biblioteconomia comparada, metodologia científica, metodologia estrutural, metodologia de sistemas.

Ao final do volume 2, Philosophical Aspects of Library Information Science In Retrospect, de 1995, Nitecki sugere a conquista e a angústia dos limites fluidos da cobertura epistemológica de um campo, ou se seja, em suas palavras, seguimos "compreendendo o caos conceitual".

\section{DICUSSÕES: NO TERRITÓRIO DO CAOS CONCEITUAL}

O Grande Khan possui um atlas em que estão desenhadas todas as cidades do império e dos reinos adjacentes, palácio por palácio e rua por rua, com as respectivas muralhas, rios, pontes, portos, rochedos (CALVINO, 2003, p. 57).

O (re)encontro com a Trilogia Nitecki nos conduz a alguns importantes elementos da epistemologia da Ciência da Informação e da reflexão sobre a própria tarefa metaepistemológica constituída nos anos 1990 pelo pesquisador. Um primeiro elemento inicial de relevo está na epistemologia histórica "esquecida". Nitecki (1993) nos permite embarcar em um vasto percurso da "(in)visibilidade" teórica do campo. Suas paisagens parecem nos dizer, no sentido wittgensteiniano de segunda ordem (a pragmática): veja isso; observe 0 uso que esse conceito ou essa técnica tem. Em outras palavras, mesmo tendo como pressuposto (apresentado no volume de 1993) um modelo lógico de análise terminológica do campo, a dinâmica (caótica) das mutações de sentido dos domínios da Ciência da Informação leva o pesquisador a recorrer a abordagens pragmáticas observando, pela via das autorias visitadas, o uso de determinados termos para a compreensão de seus significados. A Trilogia nos aponta para uma percepção anti-sincrônica e contra a a-historicidade do campo: inferimos, pode-se retirar daqui o ponto de vista, a profusão de fenômenos 
epistêmicos que constituem, desde muito antes dos anos 1990, o nosso campo. Tal percurso nos leva de Platão à Lenin, de Lenin à digitalidade dos processos informacionais.

Um segundo objeto na paisagem epistemológica de Nitecki (1993) por nós observado é a disputa terminológica do campo, como antes observado, em um franco embate naquela década, os últimos 10 anos do século XX. A terminologia niteckiana demonstra a profunda relação de noções como library, information, science, na constituição da identidade científico-acadêmico-institucional da Ciência da Informação, junto a outros conceitos. Antes de consolidada ou constituída, essa disputa terminológica tem nos anos 1990, conforme a própria operação dos significantes em Nitecki (1993) demonstra, uma vasta zona de conflito e indeterminação, um caos terminológico em ebulição.

O exercício é, como se vê, mais um percurso bio-bibliográfico, cartográfico-analítico, a tentar, de modo extremamente complicado, compreender os percursos dessa luta. Como o próprio pesquisador apontara em 1993, a Trilogia não buscava um consenso. Nos termos de Nitecki (1993), isso seria irrelevante como atividade epistemológica. Sendo o conhecimento da realidade sempre incompleto, segundo a visão niteckiana, ou seja, considerando o conhecimento como um sistema de teorias objetivas em desenvolvimento e especulações subjetivas em constante mutação, a crítica às premissas de fundamentação do campo, essa, sim, seria necessária à interpretação do esforço intelectual da Trilogia.

A metametodologia niteckiana nos leva do universal para o particular, permitindo potencialidades de replicação adaptada para análises epistemológicas locais - como observado anteriormente, a ousadia do pesquisador parte da assertiva de argumentos metafísicos para existência de uma ontologia da Ciência da Informação. Seu terceiro foco - ou seja, a produção tecida em Philosophical Ancestry Of American Library Information Science, de 1997 -, a epistemologia tecida no campo no contexto americano pontua as influências diretas e indiretas para formação do pensamento no território dos Estados Unidos da América. Assim, Aristóteles, Bacon, Kant, Heidegger são investigados em suas estruturas filosóficas aplicadas à Ciência da Informação, 
chegando até a produção americana propriamente dita, o "universo local" do pesquisador.

Dentre os obstáculos da Trilogia, nosso estudo identifica ao menos três grandes dimensões para reflexão convocada por Nitecki (1993) na crítica ao esforço intelectual empreendido décadas atrás. Tais dimensões não reduzem a qualidade do trabalho, apenas contribuem para caminhos revisitados e abertos pela Trilogia, atitude convocada pelo próprio pesquisador em seu lugar marcopoliano de narrador. São essas as dimensões: a influência anglófona como caminho pré-determinado pela formação cultural do viajante, o não aprofundamento em cartografias anglófonas anteriores e a ausência de teoria crítica, ou da dialética como método metaepistemológico para uma leitura transversal da cartografia constituída pela estrada niteckiana.

$\mathrm{Na}$ primeira dimensão por nós observada, o recorte das influências históricas pode ser reconhecido como enormemente aberto - Nitecki (1993, 1995, 1997) vai até a tradição grega para recompilar as raízes da formação do pensamento informacional contemporâneo. Se a diacronia niteckiana nos permite visitar o que há de Aristóteles, Bacon, Bergson, Einstein, Frege, Godel, Russel, Popper, sua excelente sincronia não nos apresenta a extensa produção africana e latino-americana já constituída, além de pouco reconhecer a profundidade da latinidade europeia no campo. Neste último âmbito, se fontes como Gabriel Naudé, com seu Advis pour dresser une bibliothéque, de 1627, e A missão do bibliotecário, de Ortega y Gasset, publicada em 1935, estão presentes, a produção dos anos de formação do pensamento niteckiano em tais tradições, respectiva, francesa e espanhola, é ausente. Do mesmo modo, a diacronia de travessias latino-europeias, com foco cartográfico-epistemológico, como Conrad Gesner e Gabriel Peignot, não figura na cartografia de Nitecki (1993, 1995, 1997).

Faz-se importante também indicar em relevo ausência de Paul Otlet (1934) e o Traité de Documentation, ou seja, de outro mapa de produção do conhecimento no campo. A construção do Traité se assemelha não só ao projeto niteckiano, como também aos demais (anteriores e posteriores) esforços de compreensão das influências mais remotas e contemporâneas, entre lentes 
sincrônicas e diacrônicas, de formação da estrutura das ideias em Ciência da Informação. Neste caso, ou seja, na esfera da diacronia, observamos, por exemplo, a reconstrução de um olhar sobre o positivismo do século XIX como motor influenciador do campo, mencionado e discutido por Paul Otlet, direta e indiretamente - por exemplo, as observações sobre Durkheim e Comte, bem como o diálogo teórico com o ideário de Gabriel Tarde.

Da francofonia diacrônica presente no mapa otletiano e ausente naquele niteckiano, chegamos à sincronia francófona e, para além, europeia. São diferentes as fontes que podemos mencionar, vinculadas objetivamente ao projeto do Instituto Internacional de Bibliografia. Para ampliar as observações críticas, no entanto, entre as cartografias, uma fonte parece-nos revelar, qualitativamente, essa distância e as lacunas, ou seja, Nicolas Roubakine (1998a,b).

A inexistência de um aprofundamento na identificação, análise e discussão sobre a obra roubakiniana na Triologia indica de modo semelhantemente lacunar, no plano dos mapas epistemológicos, os limites do projeto niteckiano. Para parte de nossa historiografia, dedicada aos estudos epistemológicos, ao tratarmos da fundamentação epistemológica da Ciência da Informação, a demarcação do papel pioneiro da cientificidade e do rigor metodológico do campo estaria justamente na obra de Roubakine. Uma compreensão epistemológica que se manifesta a partir desta ausência principia já um recorte abrupto de construção do campo.

Pode-se partir do reconhecimento do pensamento fundador roubakiniano no campo, seja de um modo histórico-situado, a própria obra de Paul Otlet $(1919,1934)$, seja sob uma tradição histórico-contemporânea, isto é, o trabalho de Robert Estivals $(1968,1975)$ e toda a tradição da Escola Esquematológica do campo entre os anos 1960 e 2010, em um percurso que aponta e mantém, década a década, as citações e os recuos críticos ao pensamento de Nicolas Roubakine (1998a,b), através de mapas epistemológicos de recorte francófono.

A segunda dimensão nos leva à questão da anglofonia informacional. Aqui, a crítica construtiva convocada em 1993 por Joseph Nitecki funda-se, 
inicialmente, no próprio panegírico: o pesquisador nos coloca diante do manancial de produção filosófica, epistemológica e teórica para a construção da Ciência da Informação pela via da anglofonia. Cabe-nos, pois, aqui, observar que a riqueza das fontes niteckianas abrem capítulos da-para reflexão metateórica do campo com margens para extensas revisitações em obras "(in)visíveis" de nossos fundamentos em grande parte das tradições. Destacamos, aqui, alguns "módulos" para uma disciplina epistemológica no campo extraídos da cartografia niteckiana em fontes que pouco identificadas em um cânone da própria anglofonia informacional além terras americanas como:

a) Pierce Butler, 1944, Scholarship and Civilization, e 1945, com The Intellectual Content of Librarianship - A Review, bem como 1952, com The Cultural Function of the Library;

b) J. P. Danton, com fontes, em 1934, Plea for a Philosophy of Librarianship: Philosophia vero omnium mater artium; em 1941, University Librarianship; Notes on Its Philosophy;

c) D. J. Foskett, com fontes como, em 1962, The Creed of a Librarian : No Politics , No Religion, No Morals, em 1964, Science, Humanism and Libraries, em 1967, Librarianship: Its Philosophy and History - Review, em 1968, The Intellectual and Social Change of the Library Service.

d) H. C. Wright, com produções epistemológicas como, em 1976, The Substance of Librarianship; igualmente em 1976, The Immateriality of Information; 1977, The Oral Antecedents of Greek Librarianship; 1978, Inquiry in Science and Librarianship; em 1979, The Informational Function of the Physical Datum in Human Communication; em 1981, An Anthropological Model for Librarianship; em 1982, An Interdisciplinary Philosophy of Librarianship; em 1984, From Chaos to Kaplan: A Saga of Library Literature; e, por fim, em nosso destaque, em 1986, The Symbol and Its Referent: An Issue for Library Education.

As fontes completas são facilmente reconhecidas na lógica da sistemática do mapa de Nitecki $(1993,1995,1997)$ e demonstram, como em Butler, Danton e Foskett, a trajetória de construção de ideias, os problemas clássicos de compreensão da neutralidade epistêmica do campo e seus avanços e recuos 
nas abordagens crítico-social. Como necessária, do ponto de vista da anglofonia americana, a obra de Jesse Shera recebe aqui uma cobertura reconhecida.

A linha de investigação sheriana, com sua vasta bibliografia presente na Trilogia, nos dá uma dada história diacrônica da epistemologia social, em fontes que vão da travessia dos anos 1930 aos anos 1970, como 1931, Handmaidens of the Learned World; 1941, Foundations of the Public Library ; The Origins of the Public Library Movement in New England , 1629 - 1855; 1952, Foundations of a Theory of Bibliography; 1961, Social Epistemology, General Semantics, and Librarianship; 1968, An Epistemological Foundation for Library Science; 1973, Towards a Theory of Librarianship and Information Science. Igualmente importante nesse marco de uma epistemologia social, a posição histórica, crítica e original da obra de Margaret Egan é registrada no mapa niteckiano, com trabalhos como The Library and Social Structure, de 1955, e, de 1956, Librarian's Dilemma.

Para além da anglofonia propriamente dita, os recortes nos encaminham também para um pensamento epistemológico clássico do campo. A cartografia niteckiana é rica na observação do orientalismo ranganathaniano. A obra do filósofo indiano é consideravelmente investigada, com atenção para fontes pouco visitadas até o momento na literatura internacional, como Philosophy of Public Librarianship, de 1948.

Ainda no contexto da segunda dimensão aqui destacada, outra via interpretativa nos toca. Em primeiro lugar, a ausência do aprofundamento de sínteses cartográficas dentro da própria anglofonia - ou seja, o mergulho comparado em outros mapas do conhecimento em Ciência da Informação. Podemos tratar aqui especificamente de Alvin Schrader, presente na travessia niteckiana, porém com baixa reflexividade na relação entre metodologia e resultados (em outros termos, ausência de um olhar analítico sobre as dimensões de cada cartografia). Se a Trilogia Nitecki, nos anos 1990, dá-nos a conhecer um mapa vasto de nossa construção epistemológica, por sua vez, os anos 1980 havia nos ofertado, de modo semelhante (não idêntico), um mapa de todo o nosso pensamento, sob outras configurações. Em sua tese de doutorado, Schrader (1983) questiona os contextos de formação do campo a partir do 
conceito de domínio. Seu enorme catálogo de mapas nos convoca, desde a própria produção de Nitecki $(1993,1995,1997)$ um necessário revisitar comparado-epistemológico da Ciência da Informação.

Em segundo lugar, está ausente, acima de tudo, a travessia crítica dentro da própria anglofonia. Nosso principal exemplo está na Black Librarianship e toda a resistência de uma teoria social e crítica fundada a partir da resistência da população negra nos Estados Unidos da América, com e pela via das teorias e dos métodos biblioteconômicos. O monumental trabalho de Josey e Schockley (1977), Handbook of black librarianship, e toda a produção das autorias na resistência à violência simbólica e material do racismo no ambiente biblioteconômico e das teorias e métodos biblioteconômicos para a sociedade estão ausentes da cartografia niteckiana. A pesquisa brasileira de Franciéle Garcês da Silva (2019), por exemplo, apresenta um mapa do conhecimento crítico, anti-racista, mais amplo do que a própria lente gigantesca de Nitecki (1993, 1995, 1997). No âmbito, pois, da terceira dimensão crítica aqui abordada, chegamos ao contexto da ausência de teoria crítica, ou da dialética como método metaepistemológico para uma leitura transversal da cartografia constituída pela estrada niteckiana.

Por fim, como um suplemento a este aspecto crítico-cartográfico, e não menos importante, percebe-se o distanciamento do potencial de cobertura cartográfica da Trilogia da produção em Ciência da Informação advinda de África. Seja pela via da anglofonia, seja pela via da francofonia, para apontarmos apenas as macro-dimensões hegemônicas linguísticas no fluxo científico (ou seja, mesmo no caso destas), verifica-se como ausentes tais tradições no mapa niteckiano. Não é, pois, possível identificar caminhos e aprofundamentos da enorme produção de e para África tecida no campo já constituída ali, nos anos 1990. A invisibilidade aqui está dada. Tradições remontadas pelas cartografias de Robert Estivals sobre a África francófona, por exemplo, na escola esquematológica francesa, demonstram as potencialidades de uma vasta tradição não repertoriada na Trilogia.

O escopo final de nossa reflexão nos faz retomar, entretanto, sob a via panorâmica wittgensteiniana, a extensão multicontinental trilhada pelas 
navegações niteckianas. O mapa narrado pelo pesquisador nos conduz ao pensamento antigo - desde a Grécia - de modo inaugural. Poucas são as fontes que conduzir-nos-ão objetivamente à relação entre metafísica e a epistemologia prática da construção da Ciência da Informação. Deste modo, nós somos colocamos na cartografia da Trilogia no coração de grandes reflexões filosóficas e éticas do mundo antigo que repercutem em toda nossa formação contemporânea. De Platão e Aristóteles, chegamos à discussão epistemológica do século XX sobre a natureza do conhecimento para problematizarmos as condições do conhecimento em Ciência da Informação, suas potencialidades de cientificidade, e sua condição socio-científica.

Por sua vez, se a ausência de desenvolvimento de viagens específicas e profundas sobre o papel da dialética na tessitura da epistemologia do campo, principalmente perante todas as estratégias de barbárie financiadas por teorias e métodos informacionais aplicados para e na desigualdade dos povos, negligenciando a realidade em suas assimetrias, é na Trilogia onde localizamos as raras indicações da perspectiva dialética direta em seu nascimento, na relação entre uma teoria social marxiana e o dilema informacional na literatura da Ciência da Informação. Assim, encontramos os apontamentos e análise do clássico trabalho de Trotsky, de 1924, Leninism i Bibliotechnaia Rabota (Leninism and Library Work), bem como outras obras orientadas para a compreensão do locus social das bibliotecas a partir de Lenin, como o papel de K. I. Abramov, de 1989, Dlia Massy, Dlia Tolpy, Dlia Ulitsy (For the masses, for the crowds, for the streets - Leninist theory of the development of librarianship; e, do mesmo ano, Khoroshi zdes' Biblioteki (The Libraries are Good Here - Lenin on foreign libraries).

Os segredos e as ausências, os gritos e as resistências, os relevos e as depressões da narrativa cartográfico-epistemológica de Nitecki (1993, 1995, 1997) remontam os diálogos entre o Grande Khan e Marco Polo nas Cidades Invisíveis de Ítalo Calvino (2003).

[...] o que Kublai considerava valioso em todos os fatos e notícias referidos por seu inarticulado informante era o espaço que restava em torno deles, um vazio não preenchido por palavras. As descrições das cidades visitadas por Marco Polo tinham esse dom: era possível percorrê-las com o pensamento, era possível 
se perder, parar para tomar ar fresco ou ir embora rapidamente (CALVINO, 2003, p. 19).

As paisagens (in)visíveis, posto que pouco explorados na obra niteckiana, ou objetivamente não presentes ou visíveis apenas às lentes epistemológicas, abrem para nossa epistemologia histórica as possibilidades de crer e respirar, de inspirar e de reconstituir caminhos, elaborar novas estradas, avançar na aplicação da informação para a práxis, a transformação social em seu decurso.

\section{CONSIDERAÇÕES FINAIS}

O atlas do Grande Khan também contém os mapas de terras prometidas visitadas na imaginação mas ainda não descobertas ou fundadas (CALVINO, 2003, p. 70).

Quando chegamos aos anos 1990, contexto da publicação da Trilogia, Joseph Nitecki atingia trinta anos de produção bibliográfica sobre filosofia e epistemologia da Ciência da Informação. Seu mapa epistemológico do campo pode ser compreendido, pois, como uma síntese da uma obra de décadas de viagens aos labirintos das ideias informacionais, da Antiguidade ao mundo contemporâneo.

Consideramos que ainda há muito o que aprender a partir dos mapas da Trilogia Nitecki (1993, 1995, 1997), agora deles separados trinta anos depois, seja reconstituindo seus caminhos para observação de paisagens não fotografadas, seja continuando, sob suas metametodologias, o percurso cartográfico-epistemológico do campo. Uma das principais lições está, justamente, na perspectiva diacrônica de seu "letramento cartográfico".

Do ponto de vista do exercício analítico e discursivo, observamos como caminhos importantes de reflexão metametodológica para visualização das ideias do campo, como suplemento ao leitor da Trilogia, os modos de exposição categorial para pesquisas epistemológicas tanto de Schrader, dentro de nosso próprio território em Ciência da Informação, como os procedimentos de Laudan et al. (1993) na reflexão sobre a mudança científica no plano de um método analítico-descritivo. 
A necessidade de um devir anti-epistemicida carece ser colocado como núcleo das cartografias e suas narrativas. Ainda se encontra a epistemologia histórica da Ciência da Informação da expansão de reconstrução das rotas de desenvolvimento do campo a partir das teorias críticas desse amadurecimento científico. Os exercícios tecidos no Brasil a partir dos experimentos de Vinícios Menezes (2017), Gustavo Saldanha (2019), Franciele Garces da Silva (2019) e Leyde Klebia Rodrigues da Silva (2020) são alguns exemplos-convite desse percurso no âmbito do grupo de pesquisa "Ecce Liber: filosofia, linguagem e organização dos saberes".

Por fim, a metáfora-ferramenta cartográfica nos posiciona entre Marco Polo e Kublai Khan a partir da Trilogia Nitecki. Parece-nos que a própria atividade metametodológica niteckiana nos recoloca permanentemente no devir dos mapas do conhecimento como modo de ser-saber-fazer da Ciência da Informação. Seria, pois, o campo uma ciência dos mapas epistemológicos? Desde Conrad Gesner podemos dizê-lo... Que venham e se multipliquem, pois, os mapas de epistemologias plurais e críticas da formação e do futuro dos estudos informacionais.

\section{FINANCIAMENTO}

A pesquisa foi desenvolvida a partir do fomento do Conselho Nacional para 0 Desenvolvimento Científico e Tecnológico (CNPq) e da Fundação Carlos Chagas Filho de Amparo à Pesquisa do Estado do Rio de Janeiro (Faperj).

\section{REFERÊNCIAS}

CALVINO, Italo. As cidades invisíveis. São Paulo: Biblioteca Folha, 2003.

ESTIVALS, Robert. Prospective, méthodologie et théorie de la schématisation. Schéma et schématisation, n. 1, p. 58-67, 1968.

ESTIVALS, Robert. Théorie généralle de la bibliologie, Schéma et schématisation, n. 5, p. 5-32, 1975.

JOSEY, E. J.; SCHOCKLEY, A. A. (ed.). Handbook of black librarianship. Littleton, Colorado: Libraries Unlimited, 1977. 
MOSTAFA, Solange Puntel. Epistemologia da Biblioteconomia. 1985. $147 \mathrm{f}$. Tese (Doutorado em Educação: História, Política, Sociedade) - Pontifícia Universidade Católica de São Paulo, São Paulo, 1985.

NITECKY, Joseph. Metalibrarianship: A Model for Intellectual Foundations Of Library Information Science. 1993. Disponível em:

https://web.archive.org/web/20090310180826/http://www.twu.edu/library/Nitecki I. Acesso em: 20 mar. 2020.

NITECKY, Joseph. Philosophical Aspects Of Library Information Science In Retrospect. 1995. Disponível em:

https://web.archive.org/web/20090310180826/http://www.twu.edu/library/Nitecki I. Acesso em: 20 mar. 2020.

NITECKY, Joseph. Philosophical Ancestry Of American Library Information Science. 1997. Disponível em:

https://web.archive.org/web/20090310180826/http://www.twu.edu/library/Nitecki I. Acesso em: 20 mar. 2020.

LAUDAN, Larry.; DONOVAN, Arthur.; LAUDAN, Rachel.; BARKER, Peter.; BROWN, Harold.; LEPLIN, Jarrett.; THAGART, Paul.; WYKSTRA, Steve. Mudança científica: modelos filosóficos e pesquisa histórica. Estudos Avançados, São Paulo, v. 7, n. 19, p. 7-19, 1993. Disponível em: https://www.revistas.usp.br/eav/article/view/9630. Acesso em: 20 mar. 2020.

MENEZES, Vinícios Souza de. Rasum tabulae: um limiar metafórico-escritural dos estudos da informação. 2017. 306 f. Tese (Doutorado em Ciência da Informação) - Instituto Brasileiro de Informação em Ciência e Tecnologia, Rio de Janeiro, 2017. Disponível em: https://ridi.ibict.br/handle/123456789/944. Acesso em: 20 mar. 2020.

OTLET, Paul. Traité de documentation: le livre sur le livre: théorie et pratique. Bruxelas: Editiones Mundaneum, 1934.

OTLET, Paul. L'organisation des travaux scientifiques. In: ASSOCIATION FRANÇAISE POUR L'AVANCEMENT DES SCIENCES. Conférences faites en 1919-1921. Paris: Association Française pour L'Avancement des Sciences, 1919. p. 13-50. Conferência proferida em 23 de fevereiro de 1919.

PEIGNOT, G. Dictionnaire raisonné de bibliologie, tomo I. Paris: Chez Villier, 1802.

ROUBAKINE, Nicolas. Introduction a la psychologie bibliologique. v. 1. Paris: Association Internacionale de Bibliologie, 1998a.

ROUBAKINE, Nicolas. Introduction a la psychologie bibliologique. v. 2. Paris: Association Internacionale de Bibliologie, 1998b.

SALDANHA, Gustavo Silva. Sem e cem teorias críticas em ciência da informação: Autorretrato da teoria social e o método da crítica nos estudos 
informacionais, uma bibliografia benjaminiana aberta. In: BEZERRA, Arthur Coelho; SCHNEIDER, Marco; PIMENTA, Ricardo M.; SALDANHA, Gustavo Silva. (org.). iKritika: estudos críticos em informação. 1. ed. Rio de Janeiro: Garamond, 2019. p. 171-240.

SCHRADER, Alvin. Toward a new theory of library and information science. Indiana (EUA): School of Library and Information Science, Indiana University. Thesis. 1983.

SILVA, Franciéle Carneiro Garcês da. Representações Sociais acerca das Culturas Africana e Afro-Brasileira na Educação em Biblioteconomia no Brasil. 2019. 494 f. Dissertação (Mestrado em Ciência da Informação) Universidade Federal do Rio de Janeiro/Escola de Comunicação, Instituto Brasileiro de Informação em Ciência e Tecnologia, Rio de Janeiro, 2019. Disponível em: https://ridi.ibict.br/handle/123456789/1047. Acesso em: 20 mar. 2020.

SILVA, Leyde Klebia Rodrigues da. Feminismo negro e epistemologia social: trajetórias de vida de pesquisadoras negras em Biblioteconomia e Ciência da Informação. 2020. 249 f. Tese (Doutorado em Ciência da Informação) - Instituto Brasileiro de Informação em Ciência e Tecnologia, Rio de Janeiro, 2020. Disponível em: https://ridi.ibict.br/handle/123456789/1166. Acesso em: 20 mar. 2020.

WITTGENSTEIN, Ludwig. Tratado Lógico Filosófico; Investigações filosóficas. 3. ed. Lisboa: Fundação Calouste Gulbenkian, 2002.

WITTGENSTEIN, Ludwig. Investigações Filosóficas. 2. ed. Tradução de José Carlos Bruni. São Paulo: Abril Cultural, 1979.

SOUZA, Sebastião de. Fundamentos filosóficos da Biblioteconomia. Revista de Biblioteconomia de Brasília, v. 14, n. 2, p. 189-196, jul./dez. 1986.

\title{
INVISIBLE LANDSCAPES OF THE NITECKI TRILOGY: FROM ARISTOTLE AND PLATO TO LENIN AND TROTSKY
}

\begin{abstract}
Objective: It proposes to investigate the cartographic-epistemological method of the Nitecki Trilogy and its main results for understanding the historical epistemology of Information Science. Methodology: From a methodological point of view, the pragmatics of language, under Wittgensteinian influence for diachronic research, is the basis of the result of this research, of descriptive culture, with a focus on the historical epistemologies in Information Science. The metaphor-tool of the cartographies, as a metamethod, is adopted and applied as the lens of analysis. Such tool-metaphor is accompanied by the narrative of novelist and short-story writer Italo Calvino in As Cidades Invisíveis. Results:
\end{abstract}


Nitecki Trilogy leads us to some important elements of the Information Science epistemology and the discussion on the metaepistemological task constituted in the 1990s by the researcher, with emphasis on the forgotten historical epistemology, the terminological dispute of the field and the passage from the universal to the particular. On the other hand, the problems of the Trilogy are critically observed, centrally, the closed Anglophone influence, the non-deepening in previous Anglophone cartographies and the absence of critical theory, or dialectics as a metaepistemological method for a transversal reading of cartography constituted by the Niteckian road. Conclusions: Information Science cartographic-epistemological development represents one of the central conclusive elements of the research, from the horizons revisited by the Nitecki Trilogy, together with the diachronic perspective of its cartographic literacy. Finally, it indicates the need for an anti-epistemicidal becoming to be placed at the core of future cartographies of Information Science.

Descriptors: Information Science Epistemology. Nitecki Trilogy. Epistemological cartography. Historical Epistemology. Knowledge maps.

\title{
PAISAJES INVISIBLES DE LA TRILOGÍA NITECKI: DE ARISTÓTELES Y PLATÓN A LENIN Y TROTSKY
}

\begin{abstract}
RESUMEN
Objetivo: La investigación se propone investigar el método cartográfico-epistemológico de la Trilogía Nitecki y sus principales resultados para la comprensión de la epistemología histórica de la Ciencia de la Información. Metodología: Desde un punto de vista de la pragmática del lenguaje, bajo la influencia wittgensteiniana para la investigación diacrónica, el trabajo es resultado de cultura descriptiva, con un enfoque en la reflexión sobre las epistemologías históricas del campo. La metáfora-herramienta de las cartografías, como metamétodo, se adopta y aplica como lente de análisis. Esta metáfora va acompañada de la narrativa del novelista y cuentista Italo Calvino en As Cidades Invisíveis. Resultados: El (re) encuentro con la Trilogía Nitecki nos lleva a algunos elementos importantes de la epistemología de la Ciencia de la Información y a la reflexión sobre la tarea metaepistemológica constituida en la década de 1990 por el investigador, con énfasis en la epistemología histórica olvidada, la disputa terminológica de el campo y el paso de lo universal a lo particular. Por otro lado, los problemas de la Trilogía se observan críticamente, centralmente, la influencia anglófona cerrada, la no profundización en cartografías anglófonas anteriores y la ausencia de teoría crítica, o la dialéctica como método metaepistemológico para una lectura transversal de la cartografía constituida por la carretera niteckiana. Conclusiones: El desarrollo cartográfico-epistemológico del campo representa uno de los elementos centrales concluyentes de la investigación, desde los horizontes revisitados por la Trilogía Nitecki, junto con la perspectiva diacrónica de su alfabetización cartográfica. Finalmente, el trabajo indica la necesidad de situar un devenir antiepistemicida en el núcleo de las futuras cartografías de las Ciencias de la Información.
\end{abstract}

Descriptores: Epistemología de las Ciencias de la Información. Trilogía Nitecki. Cartografía epistemológica. Epistemología histórica. Mapas de conocimiento. 
Recebido em: 29.11.2021

Aceito em: 29.11.2021 